\title{
Synergistic Increase of Oxidative Stress and Tumor Markers in PAH-Exposed Workers
}

\author{
Mei-Li Gao ${ }^{1}$, Lei Chen ${ }^{1}$, Yong-Fei Li $^{2}$, Xiao-Chang Xue ${ }^{3}$, Lan Chen ${ }^{4}$, Li-Na Wang ${ }^{5}$, \\ Walayat Shah ${ }^{6}$, Yu Kong ${ }^{1 *}$
}

\begin{abstract}
In this study, we investigated oxidative stress and tumor marker levels of polycyclic aromatic hydrocarbons (PAHs) in 136 coke oven workers and in 60 control subjects, and evaluated the correlation between oxidative stress and tumor marker levels. Questionnaires on basic demographic information were also administered. Significant differences in employment time and percentages of alcohol drinkers were observed between the control and exposed groups. PAH exposure was assessed using urinary 1-hydroxy-pyrene (1-OHP) levels and was found to be significantly higher in workers than in the controls. Significant differences $(P<0.001)$ of $M D A$, GST, LDH, NSE, Cyfra21-1, and of SCC and TNF-a $(P<0.0001$ and $P<0.05, P<0.001$, respectively $)$ levels were observed among controls and coke-oven workers, except for bottom coke oven workers. Associations between age and risk of increased TNF-a, smoking and increased GST activities, and drinking with increased MDA concentrations, were marginal $(P=0.055, P=0.048, P=0.057$, respectively $)$. The association between smoking with MDA $(P=0.004)$, NSE $(P=0.005)$, SCC $(P=0.004)$ andTNF-a $(P<0.001)$, and drinking with TNF-a levels was significant $(P=0.012)$. In addition, a significant positive correlation between oxidative stress and tumor markers was found in the present study. These results suggest that a synergistic increase of oxidative stress and tumor markers induced by PAHs may play a role in toxic responses for PAHs in coke oven workers.
\end{abstract}

Keywords: Polycyclic aromatic hydrocarbons - coke oven workers - oxidative stress - tumor markers

Asian Pac J Cancer Prev, 15 (17), 7105-7112

\section{Introduction}

Polycyclic aromatic hydrocarbons (PAHs) are a complex mixture of chemicals and a well-established group of chemical carcinogens. PAHs are generated during incomplete combustion of natural or synthetic fuels, resulting in the direct exposure of coke-oven workers to PAHs by inhalation and dermal contact (IRAC, 1983; IRAC, 1987). PAHs are metabolized by cytochrome P450 to diol epoxides capable of binding covalently to DNA, potentially initiating the carcinogenic process (Jongeneelen et al., 1987; Nerurkar et al., 2000). By targeting electrophiles generated by cytochrome P450s for conjugation with GSH, GSTs contribute to detoxification of endogenous compounds, coordinated drug and xenobiotic metabolism, as well as antioxidant functions (Balogh et al., 2008; Vaughn et al., 2011). PAHs metabolites can be detoxified by GST and uridine diohospho glucuronosyltransferase, which catalyze conjugative reactions of oxidative products, including oxidative metabolites of 1-hydroxypyrene (1-OHP) and 3-hydroxybenzo[a]pyrene (3-OH-BaP). Urinary 1-OHP is commonly used as a biomarker of internal dose for PAHs or exogenous PAH exposure (Jongeneelen et al., 1987; Nerurkar et al., 2000). Simultaneously, reactive oxygen species including superoxide, $\mathrm{H}_{2} \mathrm{O}_{2}, \bullet \mathrm{OH}$ and semiquinone radicals caused by PAHs further cause the excessive oxidative stress (Gao et al., 2010). Generally, oxidative stress is defined as an impaired balance between free radical production and antioxidant capacity resulting in excess oxidative products (Hong et al., 2009). The generation of reactive oxygen species can cause oxidative damage to DNA, proteins, or lipids in the body. Malondialdehyde (MDA), which is an end product of the oxidation of polyunsaturated fatty acids and can determine the degree of lipid peroxidation, has been used as a marker for oxidative stress (Bae et al., 2010). Additionally, the generation of oxidative stress is indicated by lactate dehydrogenase (LDH) leakage (Yang et al., 2007).

Experimental and clinical studies have shown that

${ }^{I}$ Institute of Mitochondrial Biology and Medicine, Department of Biological Science and Engineering, ${ }^{4}$ Center of Shared Experimental Facilities, The Key Laboratory of Biomedical Information Engineering of Ministry of Education, School of Life Science and Technology, Xi'an Jiaotong University, ${ }^{2}$ School of Materials and Chemical Engineering, Xi' an Technological University, ${ }^{3}$ State Key Laboratory of Cancer Biology, Department of Biopharmaceutics School of Pharmacy, Fourth Military Medical University, Xi' an, Shaanxi, ${ }^{5}$ Neurology Department, Ninth Affiliated Hospital of Medical College of Xi' an Jiaotong University, China, ${ }^{6}$ Institute of Basic Medical Sciences, Khyber Medical University, Peshawar, Pakistan *For correspondence: yukong@mail.xjtu.edu.cn, gaomeili@mail.xjtu.edu.cn 
certain tumor markers were expressed in patients with malignancy. Evidence from animal studies and reports from humans both showed tumor-initiating activity of COEs (coke oven emissions). Studies in occupational populations provide great opportunities to understand the mechanisms through which exogenous agents cause cancer (National Toxicology Program, 2011). Epidemiological studies suggest an etiological link between carcinogenic PAHs exposure and lung cancer risk in coke oven workers exposed to COEs, and coke oven workers were found to have a three to sevenfold increased risk for developing lung cancer. Also, long-term exposure to PAHs had been reported to be associated with high incidence of lung cancer in coke oven workers (Wang et al., 2010; National Toxicology Program, 2011). As for serum tumor markers, including cytokeratin 19 fragments (Cyfra21-1), squamous cell carcinoma antigen (SCC) and neuron specific enolase (NSE), have been extensively studied in lung cancer (Niewoehner and Rubins, 2003; Emin et al., 2010; Chu et al., 2011). Accumulating evidence unravels the molecular mechanisms by which inflammatory responses promote tumor progression. Tumor necrosis factor (TNF) a is one of the most potent pro-inflammatory cytokines produced in the tumor microenvironment (Takahashi et al., 2010). Earlier studies illustrated the significance of these tumor markers in the detection, prognosis and follow-up of lung cancer (Niewoehner and Rubins, 2003; Emin et al., 2010; Chu et al., 2011). However, the roles of these tumor markers in the diagnosis of coke oven workers are remain to be determined due to their relatively low sensitivity.

Based on the previous descriptions, the objective of this study was to study the levels of oxidative stress biomarkers including MDA, GST and LDH of serum in coke-oven workers. PAHs exposure was checked by means of the urinary excretion of 1-OHP. We also examined the serum tumor markers such as Cyfra21-1, SCC, NSE and TNF-a in PAHs exposure of coke-oven workers.

\section{Materials and Methods}

\section{Study Subjects}

A total of 196 male subjects were recruited from a steel plant in northern China and classified into four groups: control group, and workers from the bottom, side, and top of the coke oven based on the environmental PAHs levels of different work sites. Of whom 52, 45 and 39 workers who have worked on bottom-, side- and top-oven in the coke oven plant were served as exposure to PAHs, and these workers had been employed for at least six months. The other 60 non-coke-oven workers were staff members of the offices and hospitals of the same steel company, and served as the control group. The workers exposed to known mutagenic agents, such as radiotherapy and chemotherapy in the last 3 months, were excluded. Questionnaires were administered by trained interviewers to collect information on demographic information, including age, employment time, smoking and alcohol habits. Individuals who had smoked for 3 months were considered as smokers, and those who drank more than twice a week in the last six months were classified as drinkers. The Ethics Committee of Xi' an Jiaotong Medical
College approved the study.

\section{Determination of 1-OHP in Urine}

The determination of 1-OHP in urine was measured by the HPLC method described by Jongeneelen and Anzion (Jongeneelen et al., 1990). Aliquots of $10 \mathrm{ml}$ urine samples was enzymatically deconjugated and then transferred to primed C18 octadecyl cartridges (J. T. Baker), washed with $10 \mathrm{ml}$ of water, and eluted with $9 \mathrm{ml}$ of methanol. The components of the eluate were separated through high pressure liquid chromatography on the HP 1090 apparatus (Hewlett Packard) with the ODS C18, 200×2.1 mm column, while 1-OHP was quantitatively assayed by the fluorescence detector HP 1046 (Hewlett Packard) with $229 \mathrm{~nm}$ excitation and $400 \mathrm{~nm}$ emission wavelengths. All concentrations of 1-OHP were normalised to urinary creatinine. Urinary creatinine concentrations were analysed using a standard colorimetric method following the picric acid reaction and absorption at $520 \mathrm{~nm}$ (Baselt, 1980).

\section{Serum Oxidative Stress Markers and Serum Tumor Markers Measurement \\ The levels of serum lipid peroxidation products such} as the thiobarbituric acid adduct of malondialdehyde (TBA-MDA) were measured spectrophotometrically by a modification of the method described by Buege and Aust (1978). The spectrophotometric measurements were done with Shimadzu UV-1208 spectrophotometer (Japan). The concentrations of lipid peroxidation products were calculated as MDA concentration using the extinction coefficient for the MDA- thiobarbituric acid complex of $1.56 \times 10^{5} \mathrm{~L} / \mathrm{mol} \mathrm{cm}$ at $535 \mathrm{~nm}$. GST activity was determined as described (Habig and Jakoby, 1981). Briefly, the reaction mixture contained $0.1 \mathrm{M} \mathrm{Na}$ phosphate (pH 6.5), $30 \mathrm{mM} \mathrm{GSH,} 30 \mathrm{mM}$ 1-chloro- 2, 6 - dinitrobenzene, and serum. The optical density was measured at $340 \mathrm{~nm}$ with a spectrophotometer. LDH assay conditions were based on those described earlier (Bass et al., 1969). The assay medium for LDH contained 50 $\mathrm{mM}$ Tris-HCl buffer $\mathrm{pH}$ 7.5, 0.15 mM NADH and $1 \mathrm{mM}$ pyruvate (omitted for control). The absorptivity of NADH at $340 \mathrm{~nm}$ was $6.22 \mu \mathrm{m} / \mathrm{cm}$. The serum concentrations of NSE, Cyfra21-1, TNF- $\alpha$ and SCC were assayed by fully automatic biochemical analyzer (Mindray, BS-380, China).

\section{Statistical Analysis}

All analyses were carried out using the Statistical Package for Social Sciences (SPSS12.0). The frequencies of categorical variables, such as smoking and drinking status, between groups were compared by chi-square test. Student's t tests were used to compare the age, employment time, PAHs exposure between control and exposed groups. Multivariate logistic regression analysis of risk factors for oxidative stress and tumor markers was estimated, stratified by age, employment time, smoking and drinking status, and PAHs exposure levels as indicated by 1-OHP concentrations. Also, correlations between oxidative stress and tumor markers were analyzed. All statistical tests were two-sided with a significant level 
Table 1. Summary Data for Study Population

\begin{tabular}{|c|c|c|c|c|}
\hline \multirow[b]{2}{*}{ Variables } & \multicolumn{2}{|c|}{ Contro } & \multicolumn{2}{|c|}{ Expose category } \\
\hline & $\begin{array}{l}\text { CWs } \\
(n=60)\end{array}$ & $\begin{array}{l}\text { BOWs } \\
(n=52)\end{array}$ & $\begin{array}{l}\text { SOWs } \\
(n=45)\end{array}$ & $\begin{array}{l}\text { TOWs } \\
(n=39)\end{array}$ \\
\hline $\begin{array}{l}\text { Age (years, } \\
\text { mean (SD)) }\end{array}$ & $33.47 \pm 2.81$ & $33.67 \pm 2.66$ & $33.71 \pm 2.93$ & $33.68 \pm 2.46$ \\
\hline $\begin{array}{l}\text { Employment } \\
\text { time (years, } \\
\text { mean (SD)) }\end{array}$ & $12.93 \pm 3.41$ & $13.29 \pm 3.04$ & $14.71 \pm 3.75^{*}$ & $14.77 \pm 3.48^{*}$ \\
\hline $\begin{array}{l}\text { Current } \\
\text { smokers, } \\
\text { yes }(\%)\end{array}$ & $35(58.33 \%)$ & $34(65.91 \%)$ & $31(68.63 \%)$ & $28(71.60 \%)$ \\
\hline $\begin{array}{l}\text { Alcohol users } \\
\text { yes }(\%)\end{array}$ & s, $15(25 \%)$ & $21(40.91 \%)^{\mathrm{a}}$ & $22(49.02 \%)^{\mathrm{b}}$ & $21(53.08 \%)^{\mathrm{b}}$ \\
\hline 1-OHP & $0.54 \pm 0.22$ & $4.82 \pm 0.88 * *$ & $7.17 \pm 1.58 * *$ & $14.98 \pm 2.09 * *$ \\
\hline
\end{tabular}

Control workers: CWs; Bottom oven workers: BOWs; side oven workers: SOWs; Top oven workers: TOWs. $* P<0.05$ compared with CWs group; $* * P<0.001$ compared with CWs group; ${ }^{\mathrm{a}} P<0.05$ when compared with $\mathrm{CWs}$ by chi-square test. ${ }^{\mathrm{b}} P<0.01$ when compared with $\mathrm{CW}$ s by chi-square test. ${ }^{\mathrm{d}} 1-\mathrm{OHP}: \mu \mathrm{mol} / \mathrm{mol}$ creatinine

of $P<0.05$.

\section{Results}

\section{Main Characteristics of Study Subjects}

The relevant characteristics of exposed workers and controls are summarized in Table 1. Age, employment time, smoking status, drinking status and 1-OHP were comparable among controls and coke-oven workers working in different areas of the oven. No differences were found in the distributions of age and smoking status among controls and coke-oven workers. The employment time, the internal exposure marker of urinary excretion 1-OHP and the distribution of alcohol users was significantly increased among controls and coke-oven workers working in different areas of the oven except the employment time in bottom workers $(P<0.05, P<0.01, P<0.001$, respectively).

\section{Serum Oxidative Stress and Tumor Markers}

Figure 1 and Figure 2 show the distribution of oxidative stress and tumor markers in all subjects. Mean levels of MDA, GST, LDH and NSE, Cyfra21-1, SCC, TNF- $\alpha$ were gradually increased, followed by controls, bottom, side and top oven workers. The differences of MDA, GST, LDH and NSE, Cyfra21-1 were significant $(P<0.001)$ among controls and coke-oven workers working in different areas of the oven. The differences of SCC and TNF- $\alpha$ were significant $(P<0.05, P<0.001$, respectively) between controls and other coke-oven workers except bottom coke oven workers.

Effects of Associated Variables of Study Subjects on Oxidative Stress and Tumor Markers

Multivariate logistic regression analyses were performed with adjustment for possible confounders (that is, age, employment time, smoking status, drinking status, the level of 1-OHP) to evaluate the possible determinants of increased oxidative stress and tumor markers levels. We calculated OR values of age, employment time, smoking status, drinking status and the level of 1-OHP to compare their contribution with the measured biomarkers. As shown in Table 2 and Table 3, the association between
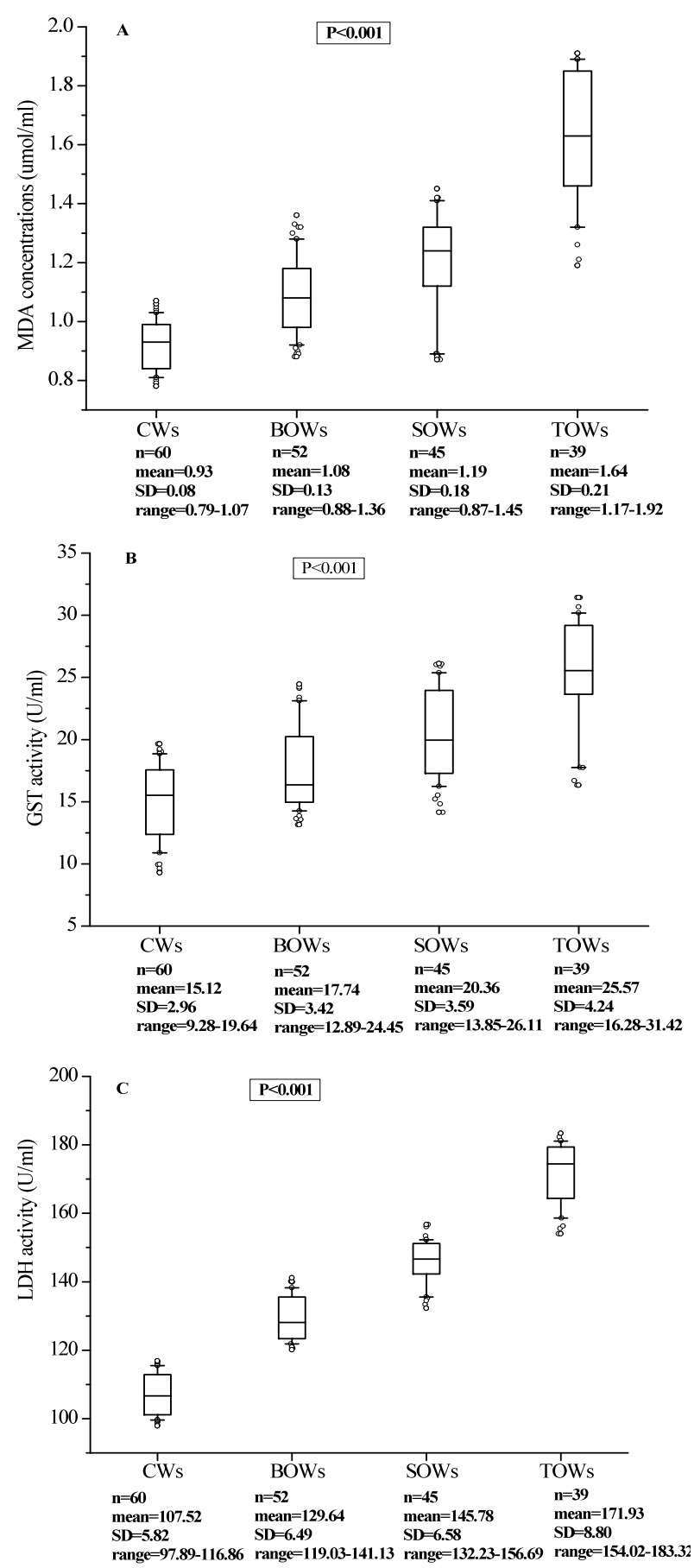

Figure 1. Concentrations of MDA, and Activities of GST and LDH in the Serum. Each sample was analyzed once. Boxes, $25^{\text {th }}$ to $75^{\text {th }}$ percentile; the horizontal line within the box represents the median value; Values outside the 10th and 90th percentiles are plotted individually. Differences between CWs and other groups were significant, $P<0.001$.

age with an increase in the risk of TNF- $\alpha$ levels, smoking with an increase in the risk of GST activities, and drinking with an increase in the risk of MDA concentrations, was marginal ( $P=0.055, P=0.048, P=0.057$, respectively). The OR values of smoking were significantly associated with MDA $(P=0.004, \mathrm{OR}=14.07 ; 95 \% \mathrm{CI}, 2.30-85.93)$, NSE $(P=0.005, \mathrm{OR}=12.71,95 \% \mathrm{CI}, 2.18-74.24)$, SCC $(P=0.004, \mathrm{OR}=5.76,95 \% \mathrm{CI}, 1.78-18.66)$, and TNF- $\alpha$ $(P<0.001, \mathrm{OR}=5.98,95 \% \mathrm{CI}, 2.57-13.87)$. Also, the 


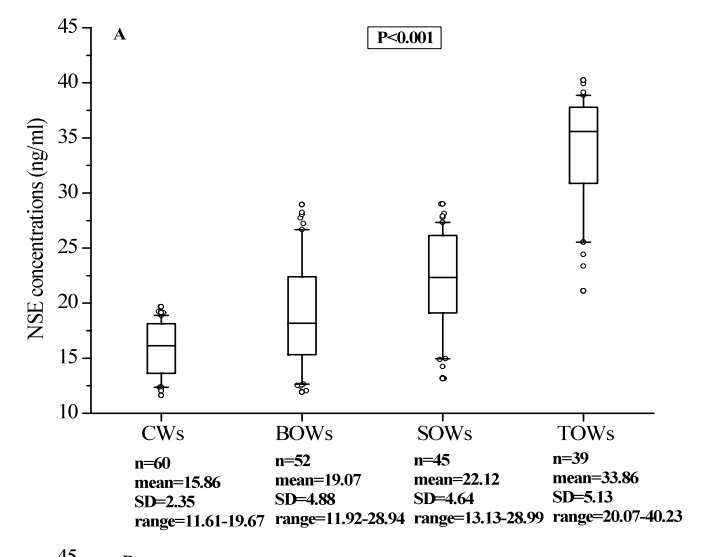

Table 2. Multivariate Logistic Regression Analysis of Risk Factors for Oxidative Stress Variables

\begin{tabular}{llll}
\hline Variable & \multicolumn{1}{c}{$\begin{array}{c}\text { MDA }^{\mathrm{f}} \\
\text { OR }(95 \% \mathrm{CI})\end{array}$} & $\begin{array}{c}\text { GST } \\
\text { OR }(95 \% \mathrm{CI}) \\
\text {-value }\end{array}$ & $\begin{array}{c}\text { P-value } \\
\text { OR }(95 \% \mathrm{CI}) \\
P \text {-value }\end{array}$ \\
\hline Age $^{\mathrm{a}}$ & 4.16 & 0.86 & 1.20 \\
& $(0.72-24.13)$ & $(0.36-2.05)$ & $(0.36-4.17)$ \\
& 0.112 & 0.734 & 0.773 \\
Employment & 1.06 & 0.82 & 6.28 \\
time $^{\mathrm{b}}$ & $(0.23-4.98)$ & $(0.35-1.94)$ & $(1.31-30.26)$ \\
& 0.943 & 0.649 & 0.022 \\
Current $_{\text {smokers }}$ & 14.07 & 2.57 & 0.19 \\
& $(2.30-85.93)$ & $(1.01-6.57)$ & $(0.02-1.68)$ \\
Alcohol & 0.004 & 0.048 & 0.136 \\
users $^{\mathrm{d}}$ & 0.16 & 2.19 & 0.93 \\
& $(0.02-1.05)$ & $(0.91-5.25)$ & $(0.21-4.09)$ \\
1-OHP & 0.057 & 0.081 & 0.921 \\
& 1423.74 & 21.42 & 831.07 \\
& $(140.76-14400.79)$ & $(8.89-51.63)$ & $(82.58-8363.17)$ \\
& $<0.001$ & $<0.001$ & $<0.001$ \\
\hline
\end{tabular}

${ }^{\mathrm{a}}$ Age: $>34$ (1), $\leq 34$ (0) (34: median level of all subjects). ${ }^{\mathrm{b}}$ Employment time $>14$ (1), $\leq 14$ (0) (14:median level of all subjects). ${ }^{c}$ Current smokers: yes (1), no (0). ${ }^{\mathrm{d}}$ Alcohol drinking: yes (1), no (0), ${ }^{\mathrm{e}} 1$-hydroxypyrene: $>5.19$ (1), $\leq 5.19$ (0) (5.19: median level of all subjects), ${ }^{\mathrm{f}} \mathrm{MDA}:>1.09(1), \leq 1.09$ (0) (1.09: median level of all subjects), ${ }^{\mathrm{g}} \mathrm{GST}:>18.13$ (1), $\leq 18.13$ (0) (18.13: median level of all subjects), hLDH: >133.65 (1), $\leq 133.65$ (0) (133.65: median level of all subjects)

Table 3. Multivariate Logistic Regression Analysis of Risk Factors for Tumor Variables

\begin{tabular}{|c|c|c|c|c|}
\hline Variable & $\begin{array}{c}\text { NSEf } \\
\text { OR }(95 \% \mathrm{CI}) \\
P \text {-value }\end{array}$ & $\begin{array}{c}\text { Cyfra } 21-1 \mathrm{~g} \\
\text { OR }(95 \% \mathrm{CI}) \\
P \text {-value }\end{array}$ & $\begin{array}{c}\text { SCCh } \\
\text { OR }(95 \% \text { CI }) \\
P \text {-value }\end{array}$ & $\begin{array}{c}\text { TNFi } \\
\text { OR }(95 \% \mathrm{CI}) \\
P \text {-value }\end{array}$ \\
\hline Age $^{a}$ & $\begin{array}{l}0.81 \\
(0.19-3.49) \\
0.776\end{array}$ & 0997 & $\begin{array}{l}1.12 \\
(0.38-3.32) \\
0.835\end{array}$ & $\begin{array}{l}0.47 \\
(0.21-1.02) \\
0.055\end{array}$ \\
\hline Employment & $\begin{array}{l}1.84 \\
(0.46-7.30)\end{array}$ & $\begin{array}{l}2.86 \\
(0.18-45.16)\end{array}$ & $\begin{array}{l}1.17 \\
(0.41-3.32)\end{array}$ & $\begin{array}{l}1.17 \\
(0.55-2.48)\end{array}$ \\
\hline time $^{\mathrm{b}}$ & 0.384 & 0.456 & 0.775 & 0.677 \\
\hline Current & $\begin{array}{l}12.71 \\
(2.18-74.24)\end{array}$ & - & $\begin{array}{l}5.76 \\
(1.78-18.66)\end{array}$ & $\begin{array}{l}5.98 \\
(2.57-13.87)\end{array}$ \\
\hline smokers $^{\mathrm{c}}$ & 0.005 & - & 0.004 & $<0.001$ \\
\hline Alcohol & $\begin{array}{l}0.62 \\
(0.14-2.62)\end{array}$ & $\begin{array}{l}0.33 \\
(0.02-5.52)\end{array}$ & $\begin{array}{l}1.29 \\
(0.44-3.77)\end{array}$ & $\begin{array}{l}2.67 \\
(1.24-5.72)\end{array}$ \\
\hline users $^{\mathrm{d}}$ & 0.517 & 0.443 & 0.644 & 0.012 \\
\hline $1-\mathrm{OHP}$ & $\begin{array}{l}411.25 \\
(74.62-2266.37)\end{array}$ & 7) & $\begin{array}{l}61.89 \\
(20.77-148.36)\end{array}$ & 6) $\begin{array}{l}3.86 \\
(1.77-8.39)\end{array}$ \\
\hline
\end{tabular}

Table 4. Correlations of the Studied Oxidative Stress and Tumor Variables Among Subjects in all Subjects

\begin{tabular}{|c|c|c|c|c|c|c|}
\hline \multirow[t]{2}{*}{ Variable } & \multicolumn{2}{|c|}{ MDA } & \multicolumn{2}{|c|}{ GST } & \multicolumn{2}{|c|}{$\mathrm{LDH}$} \\
\hline & $\mathrm{r}$ & $P$-value & $\mathrm{r}$ & $P$-value & $\mathrm{r}$ & $P$-value \\
\hline NSE & 0.972 & $<0.0001$ & 0.945 & $<0.0001$ & 0.912 & $<0.0001$ \\
\hline Cyfra21-1 & 0.939 & $<0.0001$ & 0.835 & $<0.0001$ & 0.91 & $<0.0001$ \\
\hline SCC & 0.801 & $<0.0001$ & 0.864 & $<0.0001$ & 0.71 & $<0.0001$ \\
\hline TNF & 0.728 & $<0.0001$ & 0.852 & $<0.0001$ & 0.607 & $<0.0001$ \\
\hline
\end{tabular}

association between drinking with an increase in the risk of TNF- $\alpha$ levels was significant $(P=0.012, \mathrm{OR}=2.67,95 \%$ CI, 1.24-5.72). The PAH exposure was associated with a significantly $(P<0.001)$ increased risk of having high oxidative stress and tumor markers except Cyfra21-1.

Association between Oxidative Stress and Tumor Markers

Correlations among amounts of oxidative stress and tumor markers in serum samples from individuals in different exposure groups are summarized in Table 4. There was a positive and significant correlation between oxidative stress and tumor markers in all subjects. All of the differences were significant $(P<0.0001)$. 


\section{Discussion}

In our study we investigated the effect of PAHs exposure on biomarkers of oxidative stress and tumor parameters in a group of control and coke oven workers with different working environment. We also studied possible associations between characteristics of workers, oxidative stress and tumor biomarkers.

In the present study, the coke-oven workers seemed to have been exposed to a significant high level of PAHs based on the urinary 1-OHP. The PAHs exposure of coke-oven workers in the present study was similar with that in Siwińska et al's and in Zhang's study conducted in coke oven workers and much higher than that reported by Pavanello et al in CMBN assay in coke oven workers (Zhang et al., 2001; Siwińska et al., 2004; Pavanello et al., 2008). Though the length of exposure is not, therefore, the only risk factor (Pavanello et al., 2008). Yang et al reported that the length of time spent outdoors had marginal positive associations with urinary 1-OHP levels in non-occupationally exposed Koreans (Yang et al., 2003). So, significantly higher length of employment time may promote a synergistic effect on excretion of 1-OHP in PAHs exposed side oven and top oven workers. Significant distributions for alcohol users and no significant distributions for smoking status in exposed coke oven workers were observed in the present study. On the contrary, no significant difference was found in alcohol users between control and coke oven workers in Leng et al's (Leng et al., 2004) and Zhang's studies (Zhang et al., 2001). Other studies indicated that the smoking of cigarettes significantly increase the urinary 1-OHP concentration, while alcohol consumption does not affect the urinary 1-OHP concentration (Nan et al., 2001; Yang et al., 2003). Hence, the smoking life style may not significantly affect the urinary 1-OHP concentration in this study.

Significant increases of MDA levels and $\mathrm{LDH}$ activities were observed in serum in coke oven workers. The increase of MDA levels have been shown to be a result of lipid peroxidation compared with control group (Yang et al., 2007; Gao et al., 2010). LDH release is commonly used as a marker for necrotic/oncotic cell death (Valentovic and Ball, 1998). Most cells contain LDH and when these cells are lethally injured, loss of membrane integrity can be assessed by monitoring activity of LDH in the incubation medium (Kendig and Tarloff, 2007). This is consistent with Yang et al's report that a COEsrelated dose-dependent increase in levels of DNA damage, micronuclei rate, MDA concentration, and LDH activity (Yang et al., 2007). In the present study, PAH significantly activated the GST activity. Liu et al also reported that the group exposed to COEs had significantly increased levels of GST in the PAHs exposed individuals (Liu et al., 2006). The induction of GST by PAHs suggests that GSH conjugation is involved in PAHs removal (Gowland et al., 2002; Vieira et al., 2008). As we know, GST serves as a phase II enzyme in detoxifying xenobiotics and keeping intracellular redox balance in the presence of its substrates. Hence, the increase of GST activity in coke oven workers may represent adaptation or defense against the burden of mutagens and carcinogens in the human body (Liu et al., 2006). The increase of MDA, LDH and GST is accompanied with the levels of urinary 1-OHP based on the different working environments (Figure 1). Similar results were also observed by Yang et al (2007) and Liu et al (2006). Higher levels of 1-OHP might indicate higher external exposure or faster detoxification process. So, top oven workers may expose higher PAHs, resulting in higher lipid peroxidation and LDH release, and faster detoxification by the significantly increased GST activity. Additionally, MDA contents were also affected by smoking $(P=0.004, \mathrm{OR}=14.07,95 \% \mathrm{CI}: 2.30-85.93)$ and drinking $(P=0.057, \mathrm{OR}=0.16,95 \% \mathrm{CI}$ : $0.02-1.05)$ status. Similar results can be seen in GST activities by smoking $(P=0.048, \mathrm{OR}=2.57,95 \% \mathrm{CI}: 1.01-6.57)$ and alcohol $(P=0.081, \mathrm{OR}=2.19,95 \% \mathrm{CI}: 0.91-5.25)$ status (Table 3). Several studies indicated that the levels of MDA were higher in smokers (Bindu et al., 2004; Doruk et al., 2011). The levels of peroxidation products viz., MDA, GPx and GST were increased in all the tissues of alcohol administered and smoke-exposed rats (Chelchowska et al., 2011). These may be the fact that tobacco smoke enhances lipid peroxidation and depletes antioxidant potential in smokers (Doruk et al., 2011). Also, accumulating evidence suggested that ethanol can induce oxidative DNA damage in humans (Zhang et al., 2003; Guo and Ren, 2010). LDH activities were affected by employment time $(P=0.022$, $\mathrm{OR}=6.28,95 \% \mathrm{CI}: 1.31-30.26)$, this suggest that the longer PAHs exposure may further increase the oxidative stress (Yang et al., 2007).

Significant increases of NSE, Cyfra21-1, SCC and TNF- $\alpha$ were observed in coke oven workers except SCC and TNF- $\alpha$ in bottom oven workers (Figure 2). Cyfra 21-1 is the most efficient marker for differentiating primary lung cancer from benign solitary pulmonary lesions (Seemanna et al., 1999). NSE is commonly used as markers for the differentiation of malignant and benign lesions (Seemanna et al., 1999). SCC is physiologically expressed in the skin and other squamous epithelial cells and has been proven helpful in the diagnosis of lung cancer, especially squamous cell carcinoma (Ho et al., 2000; Taniguchi et al., 2009). Accordingly, our results suggest that PAHs enhances these serum tumor markers which may further promote tumor initiation. Additionally, the levels of SCC, Cyfra21-1 and NSE were lower as compared to that in patients with advanced lung cancer (Seemanna et al., 1999; Ho et al., 2000; Taniguchi et al., 2009; Liang et al., 2013). Chu et al found that the serum levels of SCC, CEA, Cyfra21-1 and NSE were significantly higher in early-staged lung cancer patients than those in patients with benign disease. This might be used for the potential distinguishing early-staged lung cancer from benign masses (Chu et al., 2011). In addition, TNF-a is a known regulator of various inflammatory diseases including arthritis, psoriasis, inflammatory bowel disease (Tobin and Kirby, 2005; Brennan and Mcinnes, 2008; Andrisani et al., 2012), and is also involved in various pulmonary inflammatory diseases including bronchitis, chronic obstructive pulmonary disease (COPD), asthma and acute lung injury (ALI) (Mukhopadhyay et al., 2006). Accordingly, the significant increases of TNF- $\alpha$ levels in 
side and top oven workers might suggest that higher PAHs levels possibly result in inflammatory response.

Further, smoking was significantly and positively correlated $(P=0.005, \mathrm{OR}=12.71,95 \% \mathrm{CI}: 2.18-74.24)$. This is similar to the report that smoking index was negatively correlated with serum folate but positively correlated with plasma tHcy, CEA and NSE levels in Cr (VI) exposed population (Wang et al., 2013). On the contrary, Bjerner et al reported that an upper reference limit for NSE was 8.91 micro $\mathrm{g} / \mathrm{L}$ in non-smokers; smokers exhibited significantly lower levels (Bjerner, et al., 2008). SCC was also exhibited a positive and significant correlation $(P=0.004, \mathrm{OR}=5.76,95 \% \mathrm{CI}: 1.78-18.66)$ with smoking status. Our results were in agreement with Szymańska-Chabowska et al's and Cho et al's study that higher serum (squamous cell carcinoma antigen) SCC Ag levels and a distinct synergistic reaction with the number of smoked cigarettes (Szymańska-Chabowska et al., 2004; Cho et al., 2013). Smoking habits did not influence the serum concentrations of SCC Ag in lung cancer (Body et al., 1990). TNF-a levels resembled more the smoking habits $(P<0.001, \mathrm{OR}=5.98,95 \% \mathrm{CI}$ : 2.57 13.87) and alcohol consumption $(P=0.012, \mathrm{OR}=2.67$, $95 \%$ CI: $1.24-5.72)$ of the coke oven workers. Smoking has been shown to increase the production of IL-1 $\beta$ and TNF-a by macrophages (Tappia et al., 1995; Nagai et al., 1988). Recently, this was also certificated in animal models. For example, Sun et at reported that TNF-a, IL-6, and IL-10 levels of pulmonary tissue were significantly increased side stream cigarette smoke induced rat COPD model (Sun et al., 2011). Xue et al reported that cigarettesmoke-exposure induced the accumulation of TNF- $\alpha$ in cigarette-smoke-exposure-induced pulmonary vasculature impairment in rats (Xue et al., 2012). As for alcohol intake, there has been indicated that showing that moderate alcohol intake in humans reduces the production of IL$1 \beta$ and TNF-a through inhibition of NF- $\varkappa \mathrm{B}$ (Mandrekar et al., 2006). Age with an increase in the risk of TNF- $\alpha$ levels was marginal $(P=0.055, \mathrm{OR}=0.47,95 \% \mathrm{CI}: 0.21$ 1.02). In fact, a dysregulation of the innate and adaptive immune system is hypothesized as a prominent key player in the aging process which is accompanied by increased inflammatory cytokines, in particular TNF-a (Corona et al., 2011). Since no differences were found in the distributions of age in the present study, further investigations are required to confirm the association in individuals with a significant distribution of age.

A significant and positive correlation between oxidative stress and tumor markers was observed in this study. Actually, oxidative stress plays important roles in the pathogenesis of many diseases, including aging, degenerative disease, and cancer (Behrend et al., 2003), and it has been shown that oxidative mechanisms have a role in the initiation, promotion and progression of carcinogenesis (Masri, 2010).

However, serum tumor marker tests used so far are more tumor-associated than tumor-specific (Fleischhacker and Beinert, 1999). One of the main drawbacks of serum tumor markers is that high concentrations are usually found only when the disease is at an advanced stage (Seemanna et al., 1999). Cytological fluids obtained directly from tumor tissue, and because many biomarkers candidates will exist in high concentrations. Additional evaluation of these tumor markers in the cytological fluid can improve the diagnostic performance (Hur et al., 2012) and need be furthered studied in the future.

PAH are distributed in the atmosphere between gas and particulate phases, such as $\mathrm{PM}_{10}$. Recently, a series studies investigated the PAH concentrations in $\mathrm{PM}_{10}$ of different areas in Thailand. The PAH concentrations were moderately low in comparison with previous results observed in other countries. The level of genotoxicity, indicated by mutation index (MI) which was used by ames test method, was assayed in Bangkok city, Thailand. The average MI of $\mathrm{PM}_{10}$ at collected sampling sites was no significant differences (Pongpiachan et al., 2013a). The potential risks of exposure to particulate PAHs were indicated by the average values of incremental individual lifetime cancer risk (ILCR) and the concept of incremental lifetime particulate matter exposure (ILPE). The ILCR was within the range of $10^{-7} 10^{-6}$, which was close to the acceptable risk level $\left(10^{-6}\right)$ but much lower than the priority risk level $\left(10^{-4}\right)$. The higher values of ILPE of PAH congeners at traffic observatory sites were observed. This suggested a higher risk for outdoor workers, including police men, construction workers, lottery sellers, flower sellers and so on (Pongpiachan et al., 2013a; Pongpiachan 2013b). A high risk of developing lung cancer and other respiratory diseases across workers and residents living in high buildings located in Pratunam area, Thailand (Pongpiachan et al., 2013c). In addition, except lung cancer, PAHs were also implicated in prostate cancer risk and gastric cancer (Doolan et al., 2014; Behnampour et al., 2014).

In conclusion, this study suggests that PAHs significantly enhanced the oxidative stress and tumor markers in coke oven workers. In some extent, one or more characteristics may affect these biomarkers in body. A significant and positive correlation between oxidative stress and tumor markers was observed in the present study. The association found between the probability of increased oxidative stress values and tumor markers levels in post-shift urine suggests that a synergistic increase induced by PAHs in coke oven workers.

\section{Acknowledgements}

The research was supported the Shaanxi Postdoctoral Science Foundation funded project (18420024).

\section{References}

Andrisani G, Guidi L, Papa A, et al (2012). Anti-TNF alpha therapy in the management of extraintestinal manifestation of inflammatory bowel disease. Eur Rev Med Pharmacol Sci, 16, 890-901.

Bae S, Pan XC, Kim SY, et al (2010). Exposures to particulate matter and polycyclic aromatic hydrocarbons and oxidative stress in schoolchildren. Environ Health Perspect, 118, 579-83.

Balogh LM, Roberts AG, Shireman LM, et al (2008). The stereochemical course of 4-hydroxy-2-nonenal metabolism by glutathione S- transferases. J Biol Chem, 283, 16702-10. 
Baselt RC (1980). Biological monitoring methods for industrial chemicals. Davis, CA, Biomedical Publications, 207-11.

Bass A, Brdicka PE, Eyer P, et al (1969). Metabolic differentiation of distinct muscle types at the level of enzymatic organization. Eur J Biochem, 10, 198-206.

Behrend L, Henderson G,Zwacka RM (2003). Reactive oxygen species in oncogenic transformation. Biochem Soc Trans, 31, 1441-4.

Behnampour N, Hajizadeh E, Zayeri F, et al (2014). Modeling of influential predictors of gastric cancer incidence rates in Golestan Province, North Iran. Asian Pac J Cancer Prev, 15, 1111-7.

Bindu MP, Annamalai PT (2004). Combined effect of alcohol and cigarette smoke on lipid peroxidation and antioxidant status in rats. Indian. J Biochem Biophys, 41, 40-4.

Bjerner J, Høgetveit A, Wold Akselberg K, et al (2008). Reference intervals for carcinoembryonic antigen (CEA), CA125, MUC1, Alfa-foeto-protein (AFP), neuron-specific enolase (NSE) and CA19.9 from the NORIP study. Scand $J$ Clin Lab Invest, 68, 703-13.

Body JJ, Sculier JP, Raymakers N, et al (1990). Evaluation of squamous cell carcinoma antigen as a new marker for lung cancer. Cancer, 65, 1552-6.

Brennan FM, McInnes IB (2008). Evidence that cytokines play a role in rheumatoid arthritis. J Clin Invest, 118, 3537-45.

Buege JA, Aust SD (1978). Microsomal lipid peroxidation. Methods Enzymol, 52, 301-10.

Chelchowska M, Ambroszkiewicz J, Gajewska J, et al (2011). The effect of tobacco smoking during pregnancy on plasma oxidant and antioxidant status in mother and newborn. Eur J Obstet Gynecol Reprod Biol, 155, 132-6.

Cho A, Hur J, Hong YJ, et al (2013). NSCLC subtype prediction using cytologic fluid specimens from needle aspiration biopsies. Am J Clin Pathol, 139, 309-16.

Chu XY, Hou XB, Song W, et al (2011). Diagnostic values of SCC, CEA, Cyfra21-1 and NSE for lung cancer in patients with suspicious pulmonary masses. Cancer Biol Thera, 11, 995-1000.

Corona AW, Fenn AM, Godbout JP (2011). Cognitive and behavioral consequences of impaired immunoregulation in aging. J Neuroimmune Pharmacol, 7, 7-23.

Doolan G, Benke G, Giles G (2014). An update on occupation and prostate cancer. Asian Pac J Cancer Prev, 15, 501-6.

Doruk S, Ozyurt H, Inonu H, et al (2011). Oxidative status in the lungs associated with tobacco smoke exposure. Clin Chem Lab Med, 49, 2007-12.

Emin Erbaycu A, Gunduz A, Batum O, et al (2010). Pretreatment and treatment-induced neuron-specific enolase in patients with small-cell lung cancer: an open prospective study. Arch Bronconeumol, 46, 364-9.

Fleischhacker M, Beinert T (1999). Tumour markers-new aspects of an old discussion? Eur J Med Res, 4, 144 -8.

Gao M, Long J, Li Y, et al (2010). Mitochondrial decay is involved in BaP-induced cervical damage. Free Radic Biol Med, 49, 1735-45.

Gowland B, McIntosh A, Davies I, et al (2002). Implications froma field study regarding the relationship between polycyclic aromatic hydrocarbons and glutathione S-transferase activity in mussels. Mar Environ Res, 54, 231-5.

Guo R, Ren J (2010). Alcohol and acetaldehyde in public health: from marvel to menace. Int J Environ Res Public Health, 7, 1285-301.

Habig WH, Jakoby WB (1981). Assays for differentiation of glutathione S-transferase. Methods Enzymol, 77, 398-405.

Ho YJ, Hsieh JF, Tasi SC, et al (2000). Tissue polypeptide specific antigen and squamous cell carcinoma antigen for early prediction of recurrence in lung squamous cell carcinoma. Lung, 178, 75-80.

Hong YC, Park EY, Park MS, et al (2009). Community level exposure to chemicals and oxidative stress in adult population. Toxicol Lett, 184, 139-44.

Hur J, Lee HJ, Nam JE, et al (2012). Additional diagnostic value of tumor markers in cytological fluid for diagnosis of non-small-cell lung cancer. Huretal BMC Cancer, 12, 392.

IARC (1983). Monographs on the evaluation of carcinogenic risks to humans. Polycyclic aromatic compounds. Part 1. Chemical, environmental and experimental data. IARC, 32.

IARC (1987). Monographs on the evaluation of carcinogenic risks to humans. IARC, Suppl 7.

Jongeneelen FJ, Anzion RBM (1990). Analyses of hazardous substances in biological materials. Deutsche Forschungsgemeinschaft, 3, 151-69.

Jongeneelen FJ, Anzion RBM, Henderson PT (1987). Determination of hydroxylated metabolites of polycyclic aromatic hydrocarbons in urine. J Chromatgr, 413, 227-32.

Kendig DM, Tarloff JB (2007). Inactivation of lactate dehydrogenase by several chemicals: Implications for in vitro toxicology studies. Toxicology in Vitro, 21, 125-32.

Leng S, Dai Y, Niu Y, et al (2004). Effects of genetic polymorphisms of metabolic enzymes on cytokinesisblock micronucleus in peripheral blood lymphocyte among coke-oven workers. Cancer Epidemiol Biomarkers Prev, 13, 1631-9.

Liang J, Qian Y, Xu D, et al (2013). Serum tumor markers, hypoxia-inducible factor-1 alpha HIF-1 alpha and vascular endothelial growth factor, in patients with non-small cell lung cancer before and after intervention. Asian Pac J Cancer P, 14, 3851-4.

Liu AL, Lu WQ, Wang ZZ, et al (2006). Elevated levels of urinary 8-hydroxy-2-deoxyguanosine, lymphocytic micronuclei, and serum glutathione S-transferase in workers exposed to coke oven emissions. Environ Health Perspect, 114, 673-7.

Mandrekar P, Catalano D, White B, et al (2006). Moderate alcohol intake in humans attenuates monocyte inflammatory responses: inhibition of nuclear regulatory factor kappa B and induction of interleukin 10. Alcohol Clin Exp Res, 30, $135-9$.

Masri F (2010). Role of nitric oxide and its metabolites as potential markers in lung cancer. Ann Thorac Med, 5, 123-7.

Mukhopadhyay S, Hoidal JR, Mukherjee TK (2006). Role of TNF alpha in pulmonary pathophysiology. Respir Res, 7 , 125 .

Nagai S, Takeuchi M, Watanabe K, et al (1988). Smoking and interleukin-1 activity released from human alveolar macrophages in healthy subjects. Chest, 94, 694-700.

Nan HM, Kim H, Lim HS, et al (2001). Effects of occupation, lifestyle and genetic polymorphisms of CYP1A1, CYP2E1, GSTM1 and GSTT1 on urinary 1-hydroxypyrene and 2-naphthol concentrations. Carcinogenesis, 22, 787-93.

National Toxicology Program (2011). Coke-oven emissions. Rep Carcinog, 12, 120-2.

Nerurkar PV, Okinaka L, Aoki C, et al (2000). CYP1A1, GSTM1, and GSTP1 genetic polymorphisms and urinary 1-hydroxypyrene excretion in non-occupationally exposed individuals. Cancer Epidemiol Bio Prev, 9, 1119-22.

Niewoehner DE, Rubins JB (2003). Clinical utility of tumor markers in the management of non-small cell lung cancer. Methods Mol Med, 75, 135-41.

Pavanello S, Kapka L, Siwinska E, et al (2008). Micronuclei related to anti-B[a]PDE-DNA adduct in peripheral blood lymphocytes of heavily polycyclic aromatic hydrocarbonexposed nonsmoking coke-oven workers and controls. 
Cancer Epidemiol Biomarkers Prev, 17, 2795-9.

Pongpiachan S, Choochuay C, Hattayanone M , et al (2013a). Temporal and spatial distribution of particulate carcinogens and mutagens in Bangkok, Thailand. Asian Pac J Cancer Prev, 14, 1879-87.

Pongpiachan S (2013b). Vertical distribution and potential risk of particulate polycyclic aromatic hydrocarbons in high buildings of Bangkok, Thailand. Asian Pac J Cancer Prev, 14, 1865-77.

Pongpiachan S, Ho KF, Cao J (2013c). Estimation of gas-particle partitioning coefficients $(\mathrm{Kp})$ of carcinogenic polycyclic aromatic hydrocarbons in carbonaceous aerosols collected at Chiang-Mai, Bangkok and Hat-Yai, Thailand. Asian Pac J Cancer Prev, 14, 2461-76.

Seemanna MD, Beinert T, Fürst H, et al (1999). An evaluation of the tumour markers, carcinoembryonic antigen (CEA), cytokeratin marker (CYFRA 21-1) and neuron-specific enolase (NSE) in the differentiation of malignant from benign solitary pulmonary lesions. Lung Cancer, 26, 149-55.

Siwińska E, Mielżyńska D, Kapka L (2004). Association between urinary 1-hydroxypyrene and genotoxic effects in coke oven workers. Occup Environ Med, 61, e10.

Sun T, Wang X, Liu Z, et al (2011). Patterns of cytokine release and evolution of remote organs from proximal femur fracture in COPD rats. Injury, 42, 825-32.

Tappia PS, Troughton KL, Langley-Evans SC, et al (1995). Cigarette smoking influences cytokine production and antioxidant defences. Clin Sci, 88, 485-9.

Szymańska-Chabowska A, Antonowicz-Juchniewicz J, Andrzejak R (2004). Plasma concentration of selected neoplastic markers in persons occupationally exposed to arsenic and heavy metals. Med Pr, 55, 313-20.

Takahashi H, Ogata H, Nishigaki, R, et al (2010). Tobacco smoke promotes lung tumorigenesis by triggering IKK beta- and JNK1 dependent inflammation. Cancer Cell, 17, 89-97.

Taniguchi H, Sakagami J, Suzuki N, et al (2009). Adenoendocrine cell carcinoma of the gallbladder clinically mimicking squamous cell carcinoma. Int J Clin Oncol, 14, 167-70.

Tobin AM, Kirby B (2005). TNF alpha inhibitors in the treatment of psoriasis and psoriatic arthritis. Bio Drugs, 19, 47-57.

Valentovic MA, Ball JG (1998). 2-Aminophenol and 4-aminophenol toxicity in renal slices from Sprague-Dawley and Fischer 344 rats. J Toxicol Environ Health Part A, 55, 225-40.

Vaughn MP, Shinohara DB, Castagna N, et al (2011). Humanizingp-class glutathione S-transferase regulation in a mouse model alters liver toxicity in response to acetaminophen overdose. PLOS ONE, 6 , e25707, 1-10.

Vieira LR, Sousa A, Frasco MF, et al (2008). Acute effects of benzo (a) pyrene, anthracene and a fuel oil on biomarkers of the common goby Pomatoschistus microps (Teleostei, Gobiidae). Sci Total Environ, 395, 87-100.

Wang F, He Y, Guo H, et al (2010). Genetic variants of nucleotide excision repair genes are associated with DNA damage in coke oven workers. Cancer Epidemiol Biomarkers Prev, 19, 211-8.

Wang TC, Song YS, Yu SF, et al (2013). Association of folate deficiency and selected tumor marker concentrations in long-term hexavalent chromium exposed population. Int $J$ Hyg Environ Health, 217, 88-94.

Xue H, Sun K, Xie W, et al (2012). Etanercept attenuates shortterm cigarette-smoke-exposure-induced pulmonary arterial remodelling in rats by suppressing the activation of TNF-a/ NF-kB signal and the activities of MMP-2 and MMP-9. Pulm Pharmacol Ther, 25, 208-15.

Yang M, Jang JY, Kim S, et al (2003). Genetic effects on urinary 1-hydroxypyrene levels in Korean population.
Carcinogenesis, 24, 1085-9.

Yang M, Kim S, Lee E, Cheong, HK, et al (2003). Sources of polycyclic aromatic hydrocarbon exposure in nonoccupationally exposed Koreans. Environ Mol Mutagen, 42, 250-7.

Yang X, Zheng J, Bai Y, et al (2007). Using lymphocyte and plasma hsp70 as biomarkers for assessing coke oven exposure among steel workers. Environ Health Perspect, 115, 1573-7.

Zhang J, Ichiba M, Hanaoka T, et al (2003). Leukocyte 8-hydroxydeoxyguanosine and aromatic DNA adduct in coke-oven workers with polycyclic aromatic hydrocarbon exposure. Int Arch Occup Environ Health, 76, 499-504.

Zhang J, Ichiba M, Hara K, et al (2001). Urinary 1-hydroxypyrene in coke oven workers relative to exposure, alcohol consumption, and metabolic enzymes. Occup Environ Med, $\mathbf{5 8}, 716-21$. 